category, may make the division of labour in a small hospital a formidable task for the matron's office. This experiment was made possible by an imaginative housekeeping scheme sponsored by the King Edward Hospital Fund, which could be adopted more widely, particularly in the design of new hospitals.

\section{Survival in Cold Water}

In recent years the increased interest in small boat sailing and inshore recreational activities, as well as a number of major disasters at sea, have drawn attention to the need for all concerned to be familiar with the basic problems of survival in the water. Unless a man is supported by some buoyant object -ideally a life jacket-and is quickly picked up or reaches shore, he will drown. Though ability to swim well improves the chances of survival, Dr. W. R. Keatinge and his colleagues rightly point out in their paper at page 480 of the B.M.F. this week that swimming in cold water may indeed lessen the chances of survival. L. G. C. Pugh and O. D. Edholm ${ }^{1}$ have reported that a relatively thin man could lose heat more rapidly if he swam than if he kept still supported by a life jacket, and Keatinge emphasized the role of hypothermia in causing death when the Lakonia was abandoned at sea. ${ }^{2}$

The present teaching is that people who are thrown into water should stay put until picked up, provided they have adequate support such as a life jacket or floating wreckage. Swimming should be strictly limited to reaching nearby objects such as rafts. Further advice to people about to leave a sinking ship or who are sailing a small boat with a risk of capsizing is that they should put on as much clothing as possible or wear accepted survival suits. This need is second only to the use of an approved life jacket. The findings in the present paper by Dr. Keatinge and his colleagues fully support this teaching. It is significant that the subjects of the experiments were clothed, and that the cold water in which they were immersed was at $4.7^{\circ} \mathrm{C}$. $\left(40^{\circ} \mathrm{F}\right.$.), close to that encountered round the British Isles in the winter months. The breathlessness caused by sudden immersion in cold water is well known, but it is believed that this is the first attempt to measure it, and the degree to which it occurs is remarkable. Hypothermia has always been regarded as a major hazard for the survivor in cold water. G. R. Hervey ${ }^{3}$ has stated that a lightly clothed man will not live more than 15 minutes at $0^{\circ}$ C. $\left(32^{\circ} \mathrm{F}\right.$.) and cannot maintain heat balance below $20^{\circ} \mathrm{C}$. $\left(68^{\circ} \mathrm{F}\right.$.). It is apparent from this new work that respiratory distress in a swimmer may shorten this period.

Cases of sudden death on immersion in cold water have occasionally been reported as due to reflexly induced cardiac arrhythmias. The death is too sudden to be due to the inhalation of water, but clearly this is an additional factor in the causation of drowning. Though work in this field is likely to be limited because of the slight risk of cardiac failure on cold immersion the further study of the respiratory effects does deserve cautious investigation. The present paper is particularly welcome not only for its contribution to the study of survival but for its forthright emphasis on "the need for the occupants of small boats to wear a life jacket capable of keeping the face above water, and the danger in trying to swim even short distances to shore in cold water without one."

1 Pugh, L. G. C., and Edholm, O. D., Lancet, 1955, 2, 761.

2 .

- Hervey, G. R., Science News, 1955, No. 38, p. 72.

\section{Starving the Premature}

In many aspects of the management of newborn premature babies there is scope for clinical impressions. Scientific comparison of different methods of preventing the respiratory distress syndrome, of treating anoxia, or of deciding on the choice of food is beset by difficulties. There are still doctors who remain unconvinced that there is nothing to choose between the various dried foods except in price, some favouring one and some another. Some doctors still believe that there is a real danger of overfeeding full term babies, apparently because they think that human beings, unlike lambs, calves, and other animals, do not know when to stop.

It is difficult to find suitable variables which enable valid comparisons of different foods to be made. Having chosen a large number of premature babies of comparable birth weight, sex, and duration of gestation, with similar maternal causes for premature delivery, one could compare the overall survival rate, the morbidity, the gain in weight, and the incidence of vomiting, feeding problems, and oedema. Each of these presents difficulties. For instance, the survival rate depends on many factors unconnected with feeding, and different centres have different criteria for defining a live-born premature baby. Gain in weight may be confused by the presence of oedema. Few have time to record accurately the incidence of vomiting and other feeding difficulties.

There are similar problems with regard to the time at which feeding of the premature baby should commence, but more accurate tests are available in this field. The survival rate of premature babies is a poor criterion, for the quality of the survivors is what matters. Hypoglycaemia and hyperbilirubinaemia damage the brain, and it may not be possible to assess that damage until well into school age. Hence in the early or late feeding controversy the blood glucose and the serum bilirubin levels are useful data when comparing one method of feeding with another. Other useful data include the presence of acidosis or ketonuria, and perhaps the response to glucagon or adrenaline.

A. Ylppö of Finland, ${ }^{12}$ the doyen of Finnish paediatrics, has long advocated early feeding; and since Finland has almost the lowest infant mortality in the world (14 per 1,000 live births) it is unlikely that his methods were far wrong. He showed that starvation led to acidosis, undue weight loss, and haemorrhages in the gastric mucosa. He advocated feeding the premature baby with $5 \%$ glucose on the first day and glucose and breast milk on the second day. Clement Smith, of Boston, ${ }^{3}$ wrote in a discussion of Ylppö's work that "this brief résumé must close'with the confession that to be on the other side of any argument from that held by Professor Ylppö gives one a sense of vague uneasiness." Yet he

1 Ylppö, A., Zeitschr. Kinderheilk., 1916, 14, 1.

2 Ylppö, A., Ann. Paediat. Fenniae., 1954, 1, 99.

- Smith, C. A., Ann. Paediat. Fenn., 1957, 3, 261.

- Corner, B. D., Lancet, $1962,1,321$

Hubbell, J. P., Drorbaugh, J. E., Rudolph, A. J., Auld, P. A. M., Cherry, R. B., and Smith, C. A., New Engl. 7 . Med., 1961, 265, 835., Smallpeice, V., and Davies, P. A., Lancet, 1964, 2, 1349.

7 Keitel, H. G., Menduke, H., Smith, T., and Fiorentino, T., Ped. Clin. Keitel, H. G., Menduke, $\mathrm{H}$ N. Amer., 1965, 12,347.

Beard, A. G., Panos, T. C., Marasigan, B. V., Eminians, J., Kennedy, H. F., and Lamb, J., F. Pediat., 1966, 68, 329.

Wennberg, R. P., Schwartz, R., and Sweet, A. Y., F. Pediat., 1966, 68, 860.

10 Wu, P. Y. K., Teilmann, P., Gabler, M., Vaughan, M., and Metcoff, J., nediatrics 1967, 39, 733.

Rabor, I. it., Oh, W., Wu, P. Y. K., Metcoff, J., Vaughn, M. A., and Gabler, M., Pediatrics, 1968, 42, 261

12 Creery, R. D. G, Develop. Med. Child Neurol., 1966, 8, 746.

13 Creery, R. D. G., Develop. Med. Child Neurol., 1967, 9, 247.

14 Haas, L., Develop. Med. Child Neurol., 1966, 8, 773.

15 Wharton, B. A., and Bower, B. D., Lancet, 1965, 2, 969. 
favoured delayed feeding, largely on the grounds that postponement of feeds till 48 to 72 hours after birth reduced the risk of regurgitation and forestalled the development of oedema. It would be difficult to explain why a difference of 36 to 60 hours or so in the onset of feeding would materially affect the incidence of regurgitation; not much maturation of the nervous system would occur in that time. Beryl Corner ${ }^{4}$ suggested that early feeding caused distension of the stomach and embarrassment of the respirations, but not many would agree that early feeding with small quantities of milk would carry much danger of that.

Numerous workers ${ }^{5-11}$ showed that early feeding (in the first 24 hours) resulted in a higher level of blood glucose and a lower indirect serum bilirubin than late feeding (at 48 to 72 hours). R. D. G. Creery ${ }^{12} 13$ rightly pointed out that early feeding will not prevent all hypoglycaemia, but that it does reduce its incidence and severity. L. Haas ${ }^{14}$ advocated the use of milk, rather than dextrose, to prevent hypoglycaemia. B. A. Wharton and B. D. Bower ${ }^{15}$ made similar findings but noted a higher mortality in those fed early; but they used large feeds two to three hours after birth, and others have not repeated this observation.

The prevention of hyperbilirubinaemia and of hypoglycaemia is of great importance, because they damage the brain. Hyperbilirubinaemia is mainly due to haemolytic disease or prematurity, but it is aggravated by excessive doses of vita$\min \mathrm{K}$ or the administration of sulphonamides or certain other drugs. Hypoglycaemia is specially common in the smaller of twins, in the dysmature (small-for-dates baby), in babies of diabetic mothers, in babies born after maternal toxaemia, in hypothermia (cold injury), and in the respiratory distress syndrome. It seems clear that the severity of hyperbilirubinaemia and of hypoglycaemia can be reduced by early feeding of premature babies; there is no satisfactory evidence against early feeding ; and it seems irrational to starve babies for 48 to 72 hours when they have been receiving continuous nutriment in utero.

\section{Cigarettes and Atheroma}

There is some evidence that aortic atheroma is greater in cigarette smokers than in non-smokers ${ }^{1-3}$ but that its severity is not related to the patient's consumption of alcohol. ${ }^{45} \mathrm{D}$. L. Sackett and his colleagues have recently reported a study of these relationships in an investigation of 1,019 patients who died between 1956 and 1964 in a large cancer hospital at Buffalo, New York. ${ }^{6}$ All these patients had been thoroughly questioned about their lifetime's consumption of tobacco and alcohol. When they died their aortas were preserved in formalin and subsequently graded in respect of the extent and

1 Wilens, S. L., and Plair, C. M., Science, 1962, 138, 975.

- Sackett, D. L., and Winkelstein, W., Amer. F. Epidemiol., 1967, 86, 264.

3 Auerbach, O., Hammond, E. C., and Garfinkel, L., New Engl. F. Med., 1965, 273, 775 .

- Wilens, S. L., f. Amer. med. Ass., 1947, 135, 1136.

s Hirst, A. E., Hadley, G. G., and Gore, I., Amer. f. med. Sci., 1965, $249,143$.

- Sackett, D. L., Gibson, R. W., Bross, I. D. J., and Pickren, J. W., New Bngl. f. Med., 1968, 279, 1413.

'Winkelstein, W., Lilienfeld, R., Pickren, J. W., and Lilienfeld, A. M., Brit. F. Cancer, 1959, 13, 606. severity of the atheroma. Using carefully conceived analytical techniques, Sackett and his colleagues compared the grade of the aortic atheroma with the patient's age, sex, and use of tobacco and alcohol. A painstaking statistical approach was particularly important in controlling the factor of age, which confounds any assessment of the grade of atheroma, because the condition is much more severe in the elderly than it is in younger people.

There was a positive association between cigarette smoking and aortic atheroma. The severity of the atheroma increased both with the rate (packets per day) and the duration (number of years) of smoking. Those who had stopped using cigarettes before interview had a level of atheroma intermediate between those of non-smokers and current smokers. But the severity of aortic atheroma was no greater in pipesmokers and cigar-users than it was in non-smokers. There was no statistically significant increase in the severity of aortic atheroma among non-smokers who took alcohol than in a control group who neither drank nor smoked. Furthermore, the severity of atheroma in those who used both alcohol and cigarettes was not appreciably greater than in those who used cigarettes only. It was therefore deduced that alcohol had little effect on the severity of the lesion. It is noteworthy that women tended to have somewhat more severe lesions than did men.

This investigation is particularly valuable because nearly all the patients died of cancer, a condition in which there is no association with aortic atheroma. ${ }^{7}$ The historical details were impeccably recorded, and on all patients who died there was a post-mortem examination. It remains to elucidate the relationship between cigarette smoking and aortic atheroma.

\section{Depression after Childbirth}

Every general psychiatrist regularly sees women referred for emotional and behavioural abnormality in the days or weeks after giving birth. The more severe disturbances are labelled puerperal psychoses, but show the same symptom patterns as other psychoses-endogenous depression, mania, schizophrenia, subacute delirium-and the connexion, if any, with childbirth is very obscure. In some cases at least the onset of psychosis (or anyway its recognition) probably simply coincides with the obstetric event rather than results from it.

Every general practitioner sees a much larger number of puerperal women with some degree of psychiatric disturbance, though he has less training to recognize and analyse this variety of trouble. The practical questions to be answered are four: (1) How often in a series of parturient women shall we see one with abnormal emotional and behavioural reactions? (2) How will we tell which of these reactions will remit, which will require active treatment, and which will be serious, with risk of suicide or infanticide ? (3) How can we predict during antenatal care which women will have puerperal breakdowns? (4) What is the treatment, especially the prophylaxis ?

Firm answers to these questions are likely to come only from co-operative studies by general practitioner, obstetrician, 